\title{
Distributed Adaptive Dual Control via Consensus Algorithm in the Energy Internet
}

\author{
Zhang, Ning; Sun, Qiuye; Wang, Jiawei; Yang, Lingxiao
}

Published in:

IEEE Transactions on Industrial Informatics

Link to article, DOI:

10.1109/TII.2020.3031437

Publication date:

2021

Document Version

Peer reviewed version

Link back to DTU Orbit

Citation (APA):

Zhang, N., Sun, Q., Wang, J., \& Yang, L. (2021). Distributed Adaptive Dual Control via Consensus Algorithm in the Energy Internet. IEEE Transactions on Industrial Informatics, 17(7), 4848-4860.

https://doi.org/10.1109/TII.2020.3031437

\section{General rights}

Copyright and moral rights for the publications made accessible in the public portal are retained by the authors and/or other copyright owners and it is a condition of accessing publications that users recognise and abide by the legal requirements associated with these rights.

- Users may download and print one copy of any publication from the public portal for the purpose of private study or research.

- You may not further distribute the material or use it for any profit-making activity or commercial gain

- You may freely distribute the URL identifying the publication in the public portal

If you believe that this document breaches copyright please contact us providing details, and we will remove access to the work immediately and investigate your claim. 


\title{
Distributed Adaptive Dual Control via Consensus Algorithm in the Energy Internet
}

\author{
Ning Zhang, Qiuye Sun, Senior Member, IEEE, Jiawei Wang, Lingxiao Yang
}

\begin{abstract}
This paper investigates a distributed adaptive dual control (DADC) that employs both consensus algorithm and improved equal incremental principle (IEIP), to guarantee the security operation while reducing the energy consumption of the Energy Internet (EI). Since the security operation is a critical factor of the EI with the energy hub (EH), it is necessary for the EI to adjust the outputs of EHs and the system parameters which have a great influence on the performance. The consensusbased control of the EI can resolve the energy-coupling issue and accurately share the electricity and heat loads power without requiring the information of the network parameters which is hard to know. Meanwhile, the variations of system parameters caused by the droop action greatly impact the security operation of the EI. It can be adaptively recovered by executing the proposed control strategy. Furthermore, in order to reduce the energy consumption, the equipment in hubs should also be managed in view of the features of EH. The minimal loss of the energy can be achieved by utilizing the control of devices via the IEIP by considering the coupling characteristics of devices. The performance of the proposed method is demonstrated through numerical case studies.
\end{abstract}

Index Terms-Energy Internet; energy hub; distributed adaptive dual control; security operation; energy consumption; system parameters restoration.

\section{INTRODUCTION}

W ITH the growing environmental concerns, shortage of fossil fuels and rapid advances of renewable energy technology, the energy structures that multiple energy carriers are integrated like "EI" [1]-[2] were obtained momentum in studies. The EI which involves various energy forms serves the end-users through interactions and links among different sides of energy systems [3]. In this context, the model and the operation of the EI was studied by numerous researches.

Since a variety of energy convertors are involved in the EI, different energy can convert to each other and EI is more flexible than other energy networks. In this way, energy is coupled in the EI. However, there are many possible outcomes for a situation and the changes of one kind of energy may cause changes of others in the EI due to the energy-coupling. The operation of EI is more complex than other networks because of such features. The concept of EH which was introduced in the "Vision of Future Energy Networks" project as a pivotal role in the EI can better express the energy

This work was supported by the National Key R\&D Program of China (2018YFA0702200).

N. Zhang, Q. Sun and L. Yang are with the College of Information Science and Engineering, Northeastern University, Shenyang 110819, China. (e-mail: neuzhangning@163.com, sunqiuye@ise.neu.edu.cn, ylxiao66@163.com).

J. Wang is with the Center for Electric Power and Energy, Department of Electrical Engineering, Technical University of Denmark, 2800 Kgs. Lyngby, Denmark (jiawang@elektro.dtu.dk). coupling relationship [4]. How to decide the operation of EHs in EI is the key point to solve the energy-coupling issue. For better description and adjustment of the system, the modeling of the EI was studied by several researches. Reference [5] introduced an $\mathrm{EH}$ model for the EI considering the energy losses, operation efficiencies and limitation. An EH can be considered as a basic unit of the EI which provides the features such as conversion, transformation and storage for different kinds of energy carriers. Generally an EH contains a variety of devices like the transformer, the combined heat and power (CHP) and the boiler in order to satisfy the demands. Reference [6] developed the entire potential interconnections between devices of the hub. The converters and storages were simultaneously modeled in [7] and detailed assessments for the advantage of storages in the EI were also surveyed. In addition to the $\mathrm{EH}$ model with common equipment and energy forms, various EH models were investigated by some papers. Reference [8] developed an EI at urban level based on the EH model. A model which considers the electric vehicle as important storages was introduced in [9]. Along with the emphasis on clean energy, the usage of hydrogen in the EI was introduced in [10]-[13]. The EH utilizing hydrogen was first surveyed in [10]. References [11] and [12] developed the model of EH that involves the storage of hydrogen. The utilization of the nuclear energy was also studied in [12]. Reference [13] proposed an EH model which was made up of the combined cycle power plant.

Besides the studies on the modeling, a considerable amount of papers paid attention to the optimal operation of the EI. As an important issue, multiple aspects of the problem were studied. Several investigations focused on the impact of different kinds of energy markets on the scheduling of the EI. The interaction between EHs in the EI was formulated as a noncooperative game in [14]. Compared with [14], references [15]-[16] varied the game player from only the EH to both the energy company and the hub. Reference [17] investigated a low-carbon operation scheme of EHs under the carbon pricing approach which was proposed in the paper. The uncertainties in the EI were also addressed in some papers. By utilizing the proposed method, the uncertainties of electricity prices and wind power generation were solved in [18]. The uncertainty of demand also surveyed in [19]-[20] compared with [18]. An affine arithmetic-based methodology was proposed in [21] to resolve the influence of data uncertainty. Reference [22] simultaneously modeled the uncertainties of load, price and renewable energy by the hybrid scenario-based/ interval/ information gap decision theory method.

As an important part of the EI, the power system has 
TABLE I

THE COMPARISON OF RELEVANT WORKS PROPOSED IN THE LITERATURE AND THE METHOD PROPOSED IN THIS PAPER

\begin{tabular}{cccccc}
\hline Reference & Method & Energy type & Optimal operation & Power sharing & Parameter restorations \\
\hline$[17]$ & Bisection-based heuristic method & Multi-energy & $\checkmark$ & - & - \\
{$[23][24]$} & Droop control & Electricity & - & $\checkmark$ & - \\
{$[25][27]$} & Consensus-based droop control & Electricity & - & $\checkmark$ & $\checkmark$ \\
{$[29]$} & Multi-energy droop control & Multi-energy & $\checkmark$ & $\checkmark$ & - \\
Proposed & Multi-energy consensus control/IEIP & Multi-energy & $\checkmark$ & $\checkmark$ & $\checkmark$ \\
\hline
\end{tabular}

integrated distributed generation (DG) units. The droop control method which mimics the behavior of a synchronous generator was widely adopted in [23]-[24]. The droop control method that does not rely on external communication links enables "plug-and-play" of DG units. However, in practical situations, the droop control typically results in poor reactive power sharing due to the mismatched line impedances and causes the deviations of parameters like frequency and voltage. In this context, the consensus algorithm based on multi-agent control theory was utilized to resolve the problem. Reference [25] studied the consensus-based droop control for the active power sharing. The consensus-based reactive power sharing control strategy was presented in [26] by using a distributed adaptive virtual impedance control. References [27]-[28] realized accurate power sharing and restorations for both voltage and frequency by using distributed secondary voltage and frequency control. However, the methods in [23]-[28] focus on the electricity only and applications to EI is ignored. The study on EI is important for including multiple kinds of energy and their couplings.

Most of studies of the EI dealt with the modeling and optimal scheduling. However, the control and security operation of the EI was considered by few researches which is the most essential and important requirement. Reference [29] presented a control strategy that can proportionally allocate the EH outputs to avoid overload. But the knowledge of the network parameters like line resistances, which is hard to obtain, is necessary for the method to realize the power sharing. Moreover, the system parameters of the EI will be deviated from nominal values after the proportional allocation, and the performance of the EI is highly influenced by the deviation which may even cause the instability of the EI. Table I summarizes taxonomy of proposed methodologies. In this paper, the contribution can be expressed as follows:

1) A DADC that employs both consensus algorithm and IEIP is proposed to guarantee the security operation of the EI while minimizing the energy consumption.

2) The control method of the EI based on the consensus algorithm and characteristics of the EI is presented. The control approach can solve the energy-coupling issue and proportionally allocate the outputs of $\mathrm{EH}$ without requiring the information of the network parameters that is difficult to know.

3) The system parameters restoration in view of a dynamic adaptive consensus control is presented to adjust the parameters of EI, which will be deviated from the nominal values due to the droop action and highly impact the security operation and performance of the EI.

4) To appropriately regulate the constituent equipment of $\mathrm{EH}$

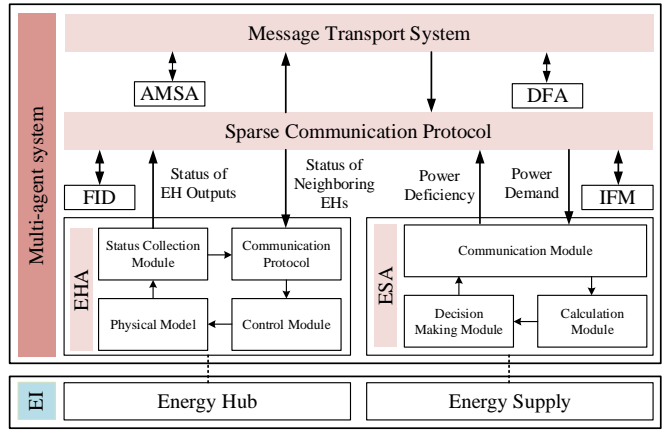

Fig. 1. Architecture of multi-agent system

and reduce the energy consumption, the control of devices based on the IEIP is proposed with the consideration of the coupling characteristics of the devices.

This paper is organized as follows: Section II presents the architecture of multi-agent system for the EI and proposes the DADC which realizes the power sharing and the parameter recovery. Section III introduces illustrative cases to describe the DADC applied to a simulated EI. In Section IV, the conclusion of the paper is provided.

\section{The Distributed Adaptive Dual Control for THE INTEGRATED ENERGY SYSTEM}

\section{A. Architecture of the Proposed Control Based on the Multi- agent System}

To avoid overload problem and guarantee the security operation for the EI, the load power should be shared accurately and the system parameters of the EI should also be restored when the deviation occurs. To solve the issues, the DCDA is presented. In this paper, the controller structure utilized in the EI is designed on the basis of a multi-agent system [30]-[32]. Fig. 1 shows the architecture of the multi-agent system. The supply side and each EH are controlled by different agents which avail of the cooperative, intelligent, and adaptive features of the multi-agent system. Each agent has its own functions and goals. Based on the functions and goals, there are two agents designed for the proposed controller and another two normal agents in the multi-agent system. The agents designed for the controller include the energy supply agent (ESA) and the EH agent (EHA). Another two necessary agents are the directory facilitator agent (DFA) and the agent management service agent (AMSA) [30]. Moreover, the EI also installs the fault isolation device (FID) and the intelligent fault management (IFM) which are not argued in this paper. The agents are described as follows:

1) Energy Supply Agent: The ESA is mainly utilized to dispose the information from EHAs and calculate the power 
flow between EH and energy supply side in this paper. In the multi-agent system of the EI, the ESA is an agent to ensure the energy supply for the EHs.

2) Energy Hub Agent: The EHA is used to achieve the distributed coordinated control among different EHs. Meanwhile, the control objectives of each $\mathrm{EH}$ are realized by the agent. Since the EH is the basic unit of the EI, the EH controlled by the agent plays a decisive role in the EI operation.

3) Agent Management Service Agent: The function of the AMSA is like a white page, which can maintain the directory of the agents in the EI.

4) Directory Facilitator Agent: The function of the DFA is like a yellow page, which can maintain the directory of the agents and the services they can offer to other agents.

\section{B. The Control of Outputs Based on Consensus Algorithm}

Since the proportional power sharing and the restoration of EI parameters cannot be reached spontaneously, it is necessary to propose a control strategy for the outputs of EH. The model of the EI in this paper is a classical model. All system parameters like pressure, frequency are important and common parameters in theory [33] and practice. As the basic energy unit in the EI, EH can receive multiple energy carriers and have the ability to convert and deliver energy. The EH model made of the transformer, the boiler, the CHP and the furnace is shown in Fig. 2 [5][29]. In the EH model, the transformer is the power delivery device for electricity. The CHP, the boiler and the furnace are the energy conversion devices which can realize the conversion between different energies. Based on the characteristics of the district heating sub-network, a control strategy for heat output is proposed and can be expressed as follows:

$$
L_{h}^{2}=L_{h N}^{2}+k_{p}\left(p_{N}-p\right),
$$

where $L_{h}$ and $L_{h N}$ are heat output power and nominal heat output power of EH, respectively. The adjustment coefficient for heat output is denoted by $k_{p}$. The outlet pressure and nominal outlet pressure of $\mathrm{EH}$ are represented by $p$ and $p_{N}$, respectively. Moreover, the adjustment coefficient $k_{p}$ for each $\mathrm{EH}$ has the relationship to share the power proportionally:

$$
\frac{L_{h N 1}^{2}}{k_{p 1}}=\frac{L_{h N 2}^{2}}{k_{p 2}}=\cdots=\frac{L_{h N n}^{2}}{k_{p n}} .
$$

As shown in (1), the control method is a flow control which can improve the respond speed of the system. But the presented strategy can not reach the proportional power sharing since the resistance of transmission pipeline for each $\mathrm{EH}$ is different. Furthermore, the pressure of the network is deviated which will badly impact the performance of the system by using the strategy.

An adaptive power control based on consensus is designed to achieve accurate power sharing. The heat output power $L_{h}^{2}$ is utilized to construct the first-order and linear multiagent system dynamic, and to design corresponding consensus control protocol. Let $L_{h}^{2}=H$. The first-order and linear multiagent system dynamic can be expressed as:

$$
\frac{\dot{H}_{i}}{k_{p i}}=u_{H i}
$$

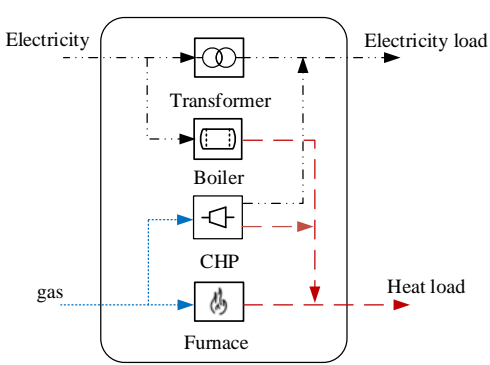

Fig. 2. EH with electricity, natural gas, and heat systems.

In view of the consensus control, the $u_{\mathrm{Hi}}$ as the mismatch of the heat power is chosen, according to the information of neighbors for each $\mathrm{EH}$ and its own information. The auxiliary control $u_{H i}$ can be written as:

$$
u_{H i}=-R_{H} q_{H i},
$$

in which the coupling gain of heat power is denoted by $R_{H}$ and the local neighbor heat power sharing error is represented by $q_{H i}$. To proportionally allocate the output of energy, the consensus protocol based on (2) should be designed that $\frac{H_{i}}{k_{p i}}$ of each EH should be equal. Namely, the heat power sharing error $q_{H i}$ can be formulated as:

$$
q_{H i}=\sum_{j=1, j \neq i}^{n} a_{i j}\left(\frac{H_{i}}{k_{p i}}-\frac{H_{j}}{k_{p j}}\right),
$$

in which the elements in the adjacency matrix are described by $a_{i j}$, and the connected situation variation of $\mathrm{EH}$ agents can be reflected by the elements. Then the entire system can be expressed as:

$$
\begin{gathered}
\frac{\dot{\boldsymbol{H}}}{\boldsymbol{k}_{p}}=\boldsymbol{u}_{H} \\
\boldsymbol{u}_{H}=-\boldsymbol{R}_{H} \boldsymbol{q}_{H} \\
\boldsymbol{q}_{H}=D \frac{\boldsymbol{H}}{\boldsymbol{k}_{p}}
\end{gathered}
$$

in which the global variables are described as $\frac{\dot{H}}{k_{p}}=\left[\frac{\dot{H}_{1}}{k_{p 1}}, \ldots, \frac{\dot{H}_{n}}{k_{p n}}\right]^{T}, \quad \frac{H}{k_{p}}=\left[\frac{H_{1}}{k_{p 1}}, \ldots, \frac{H_{n}}{k_{p n}}\right]^{T}$, $\boldsymbol{q}_{H}=\left[q_{H 1}, \ldots, q_{H n}\right]^{T}$ and $\boldsymbol{u}_{H}=\left[u_{H 1}, \ldots, u_{H n}\right]^{T}$.

Then the mismatch need to feed to a proportional integral (PI) controller $D_{i}(s)$ and a correction term $\delta H_{i}$ is generated by the PI controller. The correction term $\delta H_{i}$ which is utilized to update the constant term in (1) can be expressed as :

$$
\delta H_{i}=D_{i}(s) u_{H i}
$$

To restore the pressure deviation introduced by the traditional control method, the dynamic consensus-based pressure control is utilized. The control method can compensate the estimated pressure which is the evaluated value during the consensus control. Since the pipeline resistance of each EH is different, the hub outlet pressure cannot be controlled at an identical value. On the other hand, the outlet pressures for all EHs should be controlled within an acceptable range of the rated pressure. The consensus protocol of the proposed control is presented as:

$$
\bar{p}_{i}(t)=p_{i}(t)+R_{p} \int \sum_{j=1, j \neq i}^{n} a_{i j}\left(\bar{p}_{j}(t)-\bar{p}_{i}(t)\right) d t,
$$


where $\bar{p}_{i}$ and $p_{i}$ are the estimate pressure and outlet pressure of $i$ th $\mathrm{EH}$, respectively. $R_{p}$ is the coupling gain.

Then the estimated pressure $\bar{p}_{i}$ is in comparison with the reference pressure of district heat network. The pressure mismatch is expressed as:

$$
u_{p i}=p_{r e f}-\bar{p}_{i},
$$

where $u_{p i}$ is the pressure mismatch between estimated pressure and reference pressure. The reference pressure is denoted by $p_{r e f}$. To generate the pressure correction term $\delta p_{i}$, the pressure mismatch $u_{p i}$ is fed to a PI controller $G_{i}$. The correction term $\delta p_{i}$ is shown as:

$$
\delta p_{i}=G_{i}(s) u_{p i} .
$$

In order to restore the estimated pressure to the reference pressure of the heating system, the local pressure set point need to be updated by utilizing the pressure correction term $\delta p_{i}$ obtained from the pressure controller.

Similar to the control for heat output which is shown in (1), a control method based on the droop characteristics in the modern power systems and the features of hub is investigated to decide the electricity output of hub. The control method can be denoted as:

$$
L_{e}=L_{e N}+k_{q}\left(f_{N}-f\right),
$$

where the electricity output power and nominal electricity output power of EH are represented by $L_{e}$ and $L_{e N}$, respectively. $k_{q}$ is the adjustment coefficient for electricity output. The measured frequency and nominal frequency of electricity network are denoted by $f$ and $f_{N}$, respectively. With the existing low-pass filter, the control method for $i$ th EH can be deduced for:

$$
\tau_{i} \dot{L}_{e i}=-L_{e i}+L_{e i N}-k_{q}\left(f_{N}-f\right),
$$

where the time constant of the low-pass filter is denoted by $\tau_{i}$. Just like (2), the adjustment coefficient $k_{q}$ for each EH has the relationship to share the power proportionally:

$$
\frac{L_{e N 1}}{k_{q 1}}=\frac{L_{e N 2}}{k_{q 2}}=\cdots=\frac{L_{e N n}}{k_{q n}} .
$$

The electricity loads power can be shared by EHs that utilize the control method shown in (1) in view of the characteristic of the frequency in electricity network. However, the frequency of the network will be deviated during the controller operation. Since the grid is sensitive to changes in frequency, the frequency deviation may cause great influence on the security operation of electricity network.

For purpose of compensating the frequency deviation, the dynamic consensus-based frequency control is proposed. Combing with (14) and the frequency control, the control of electricity output for EH can be expressed as:

$$
\tau_{i} \dot{L}_{e i}=-L_{e i}+L_{e N}-k_{q}\left(f_{N}-f\right)+u_{L_{e i}},
$$

where $u_{L_{e i}}$ is the input for the electricity output control. To realize the the purpose of frequency control, the dynamic consensus-based controller is shown as:

$$
\lambda_{f_{i}} \dot{u}_{f_{i}}=-\alpha_{i} e_{f_{i}}-\beta_{i} \sum_{j=1, j \neq i}^{n} a_{i j}\left(\frac{L_{e i}}{L_{e i N}}-\frac{L_{e j}}{L_{e j N}}\right),
$$

$$
e_{f_{i}}=\sum_{j=1, j \neq i}^{n} a_{i j}\left(f_{i}-f_{j}\right)+g_{f i}\left(f_{i}-f_{r e f}\right),
$$

in which $\lambda_{f_{i}}, \alpha_{i}$ and $\beta_{i}$ are all the proportional gain in the proposed controller. The mismatch of local frequency tracking for adjacent nodes is represented by $e_{f_{i}}$. The gain for virtual leader frequency is denoted by $g_{f i}$.

According to (17) and (18), the controller can be divided into two parts: The first part is to track the frequency mismatches between $i$ th $\mathrm{EH}$ and adjacent nodes meanwhile to follow the frequency of the virtual leader. By tracking the frequency mismatches, EHs can spontaneously adjust the outputs until reach the same frequency to make the system stability. Moreover, a virtual leader is built and the frequency of the leader always keep at the reference value. The leader is followed by every hub in order to make the frequency back to the reference frequency $f_{r e f}$. The first part of the controller can ensure the security operation and restore the deviation of the frequency. However, the output of EH cannot be proportionally allocated by only using the first part of the controller, since the $u_{f}$ for hubs converges to different value. Therefore, the second part of the controller is proposed to achieve the proportional allocation of the EH output as shown in (17). The electricity loads will be proportionally shared if $L_{e i} / L_{e i N}=L_{e j} / L_{e j N}$. For each EH, the derivative of $u_{f_{i}}$ trending to 0 means that the $u_{f_{i}}$ converges to value that makes the frequency back to reference value and the loads proportionally shared.

The stability of the proposed method can be proofed by utilizing the Lyapunov stability theory and the Laplace transformation [34]. For the length of the paper, the proof process is not described in detail temporarily.

In this context, the control of EH outputs based on consensus algorithm can proportionally allocate the outputs of EH without requiring the information of the network parameters. Meanwhile, the system parameters which will be deviated from the nominal values due to the droop action can also be restored by utilizing the control method.

\section{The Control of Devices Based on Improved Equal Incre- ment Principle}

The electricity and heat outputs can be determined by utilizing the proposed control method. Nevertheless, only be aware of the outputs unable to decide the operating of $\mathrm{EH}$ because of the complex coupling of internal equipment. Actually, most objectives of the EH are achieved by adjusting the constituent devices of hub. Since a crucial role of hub is to reduce the energy cost, it is necessary to investigate a control method for devices to decrease the energy consumption.

The equal incremental principle is a classic method which is widely applied in the engineering practices [35]-[36]. Based on the characteristics of the devices in the $\mathrm{EH}$, the principle in improved in this paper to solve the optimal operation of hub if the output is decided. The IEIP is shown as:

$$
\left\{\begin{array}{l}
\sigma_{z, r}=\sigma_{z}^{*}, Q_{r}^{\min }<Q_{r}<Q_{r}^{\max } \\
\sigma_{z, r} \leq \sigma_{z}^{*}, Q_{r}=Q_{r}^{\max } \\
\sigma_{z, r} \geq \sigma_{z}^{*}, Q_{r}=Q_{r}^{\min }
\end{array},\right.
$$




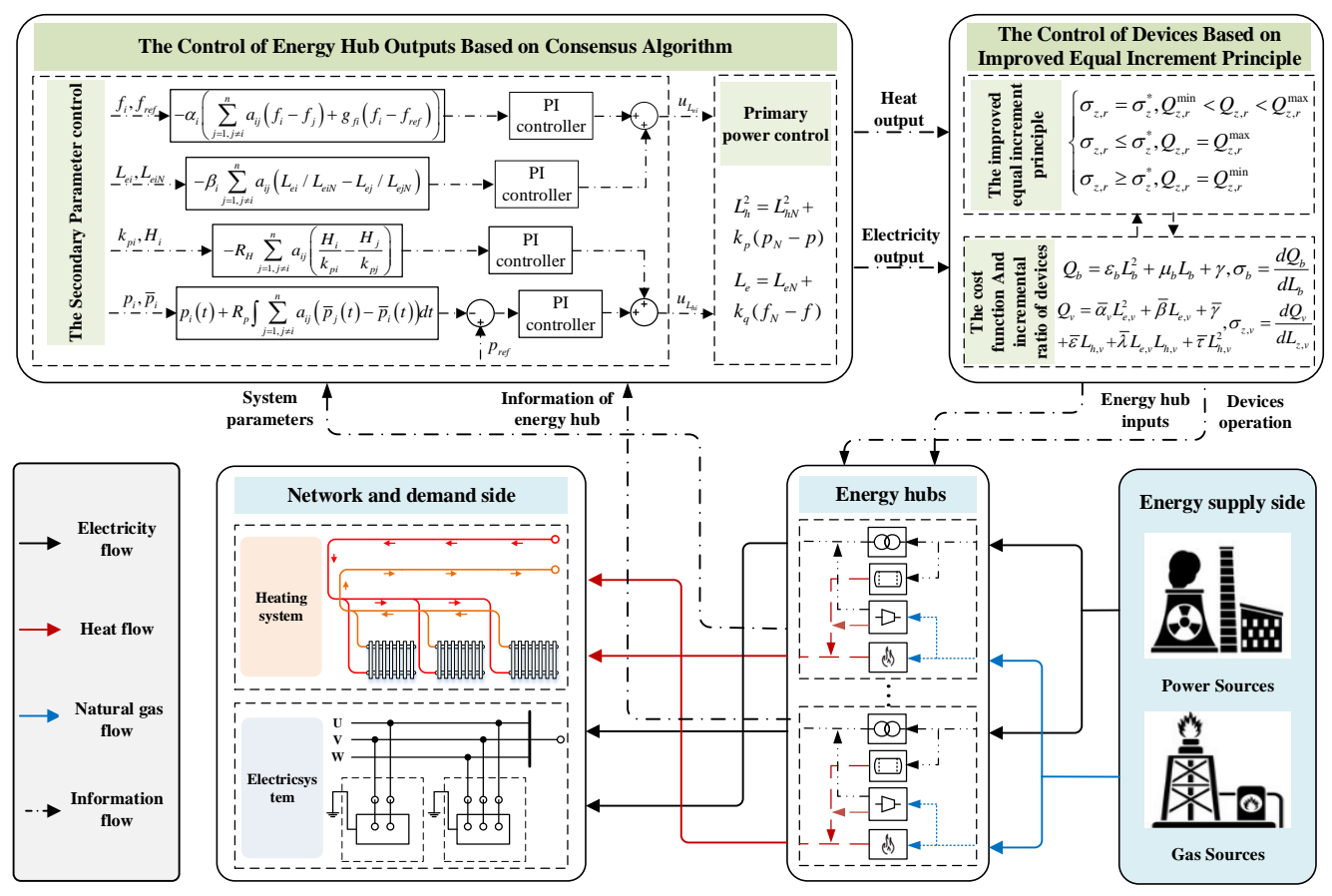

Fig. 3. The complete running process of the EI utilized the DADC.

where $Q$ is the input of inner device. $z$ represents various energies and $\forall z \in e, h . \sigma^{*}$ is the standard incremental ratio of cost, and $\sigma_{r}$ is the incremental ratio of cost for device $r$.

Generally, there are multiple converters in EH model. As shown in Fig. 2, the converters can be divided into two categories: the converter only outputs one kind of energy (COE) and the converter outputs multiple kind of energies (CME). Different COEs have different consumption. Nevertheless, the fuel cost usually can be expressed by a quadratic form [37]. The consumption function of $\mathrm{COE}$ is denoted as:

$$
Q_{b}\left(L_{b}\right)=\varepsilon_{b} L_{b}^{2}+\mu_{b} L_{b}+\gamma,
$$

where $\varepsilon, \mu$ and $\gamma$ are the cost parameters of the COE. $Q_{b}$ and $L_{b}$ state the corresponding input and output of COE $b$. The incremental ratio of COE can be shown as:

$$
\sigma_{b}=\frac{d Q_{b}\left(L_{b}\right)}{d L_{b}}
$$

The cost function of CMEs for electricity and heat generation like CHP can be denoted as:

$$
Q_{v}\left(L_{e, v}, L_{h, v}\right)=\bar{\alpha}_{v} L_{e, v}^{2}+\bar{\beta} L_{e, v}+\bar{\tau} L_{h, v}^{2}+\bar{\varepsilon} L_{h, v}+\bar{\lambda} L_{e, v} L_{h, v}+\bar{\gamma},
$$

in which $[\bar{\alpha}, \bar{\beta} \ldots, \bar{\gamma}]$ stands for the cost parameters for CME. The index for CME is represented by $v$.

The incremental ratio of fuel consumption function for $\mathrm{CME}$ is described as:

$$
\sigma_{z, v}=\frac{\partial Q_{v}\left(L_{e, v}, L_{h, v}\right)}{\partial L_{z, v}} .
$$

The entire incremental ratios of component elements in $\mathrm{EH}$ are decided by (21) and (23). Hence, the elements outputs can be controlled based on the IEIP. Furthermore, each device input can be obtained according to (20) and (22). As shown in Fig. 2, the inputs of EH are equal to the total inputs of the inner devices. Likewise, the outputs of energy share the same feature.

As denoted in (19)-(23), the control approach in terms of the IEIP of EI can determine the operation of the devices in $\mathrm{EH}$.

The DADC can be realized by combining the consensusbased outputs control and the control of devices based on IEIP. In this regard, the complete running process of the EI utilized the DADC is described by Fig. 3. The EHs obtain the energies from supply side and satisfy the demand side. When loads vary, system parameters of the EI like pressure and frequency will be changed in view of the features of the EI. The contents of communication between each EH agent also contain the necessary information for the EH control. As shown in Fig. 3, the energy supplied by EH needs to go through the corresponding network to satisfy the load. And the parameters of the network lines will influence the results of system operation. The EH controlled by DADC only needs to detect the variations of the parameters and the information of neighbors without the information of the line resistances, which is hard to obtain. Fig. 3 also shows three parts of the EI: energy supply, energy conversion and delivery, energy demand. The energy supply side in Fig 3 stands for all kinds of power sources and gas sources. The EH in the paper is considered as a unit for energy conversion. The part of energy generation is transferred to the energy supply side.

In the EI, different energy networks in the EI are coupled by the conversion devices and the energy transmission of each energy network is independent because of the particularity of different network lines. Each energy network has its own 
characteristics. The power system needs rapid response to ensure the stability. Since some equipment in $\mathrm{EH}$ respond slowly, EH will immediately obtain the energy from energy sources like the DG and battery to satisfy the load changes by the control of outputs, so that EH can complete the response in milliseconds and ensure the security operation of the system. At this point, other equipment start to be adjusted based on the control of devices. The inputs of $\mathrm{EH}$ will also be regulated. The operation of EH can meet the requirements of internal control and the demand of electricity and heat. In this way, the changes of power load and thermal load will not affect each other and avoid the instability of the system. The energycoupling is reflected in the internal and input terminals of $\mathrm{EH}$.

In this paper, security operation is to achieve power sharing and restore the parameters. As shown in the introduction, the proportional sharing of load supply and the restorations of parameters like frequency and voltage were realized by utilizing consensus algorithms in electrical power systems in references [25]-[28] for security operation. However, the methods in the references cannot be used in the EI because the characters of other kinds of energies are different from electricity and the energy is coupled due to the energy conversion. Compared with these methods, the DADC can realize the proportional sharing of load supply of EI and reduce the energy consumption based on the EH and the different characters of different kinds of energies. Reference [29] proposed a control method that can proportionally share the loads of EI to avoid overload. But the knowledge of the network parameters like line resistances is necessary in reference [29] to realize the power sharing. The deviations of system parameters of the EI will also occur after the proportional allocation due to the droop action. And the deviations will highly influence the performance of the EI. In this paper, the proposed DADC can proportionally allocate the outputs of $\mathrm{EH}$ without requiring the information of the network parameters and adjust the system parameters of EI. All EHs will not overload or work in extreme cases so that some problems such as the overheating and excessive wear of EHs can be avoided. Meanwhile, the parameters can be restored to avoid the system instability caused by the deviations of the system parameters. Based on the IEIP which can be proved by Lagrange multiplier method, the issue of reducing energy consumption is transferred to achieve the equal incremental of each device. The constituent equipment of $\mathrm{EH}$ can also be appropriately regulated and the energy cost can be reduced by utilizing the IEIP-based inner devices control of DADC.

\section{Simulation Results And Analyses}

The simulation model with three EHs is designed based on a local energy system in an industry zone in Changsha, China. Meanwhile, the model with communication links among EHs is shown in Fig. 4. Each EH shares the same construction as Fig. 2. In order to satisfy the requirement of component elements, all EHs are connected to gas and electricity networks.

The capacities and the coefficients of COEs like furnaces, boilers are denoted in Table II. Table III describes the coefficients and the capacities of CHPs. The reference frequency is $50 \mathrm{~Hz}$ and the reference pressure is $1.1 \mathrm{MPa}$. The reactive power

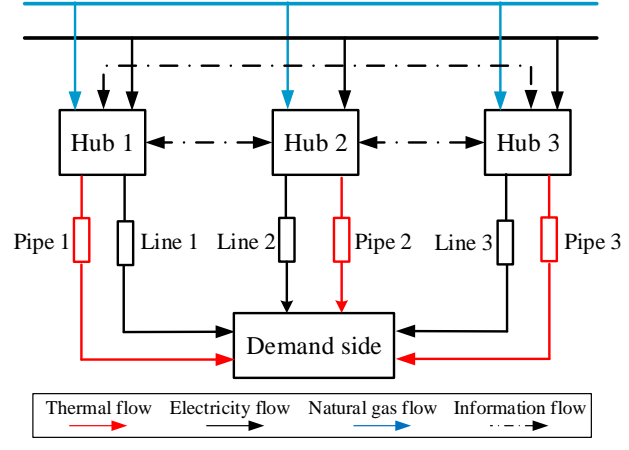

Fig. 4. EHs supply energy to demand.

TABLE II

EFFICIENCY AND CAPACITY OF DEVICES

\begin{tabular}{cccccc}
\hline Hubs & Devices & $\varepsilon$ & $\mu$ & $\gamma$ & Capacity $(\mathrm{kW})$ \\
\hline 1 & The gas furnace & 0.00097 & 0.98615 & 23.38 & 640 \\
1 & The electric boiler & 0.00096 & 0.98825 & 25.62 & 640 \\
1 & The transformer & 0.00061 & 0.99662 & 30.13 & 2800 \\
2 & The gas furnace & 0.00031 & 0.87824 & 22.63 & 320 \\
2 & The electric boiler & 0.00025 & 0.90625 & 24.33 & 320 \\
2 & The transformer & 0.00013 & 0.93125 & 28.35 & 1400 \\
3 & The gas furnace & 0.00026 & 0.96922 & 30.51 & 160 \\
3 & The electric boiler & 0.00028 & 0.95351 & 22.23 & 160 \\
3 & The transformer & 0.00011 & 0.93652 & 21.63 & 700 \\
\hline
\end{tabular}

and voltage are controlled in the cases by using the method in reference [29] which provides a simple and intuitive tradeoff between the conflicting goals of voltage regulation and reactive power sharing. Due to the space limitation and the control of voltage and reactive power is not the focus of this paper, the performances of voltage regulation and reactive power sharing will not described in detail.

The DADC realizes power sharing and parameter restoration through real-time response to load changes. So the change trends of load are not necessary for the DADC. The DADC can handle the change of loads, even the extreme fluctuations of the load can still be handled as shown in Fig. 9. The loads data is synthetic to show the performance of the DADC in many situations such as decrease and increase of loads, the extreme fluctuations of the load and so on.

All cases share the same loads before the 300s. There are $3300 \mathrm{~kW}$ electricity loads and $1600 \mathrm{~kW}$ thermal loads integrated into the energy system. The consequence data before the 300s is represented in Table IV. The consequence data after the $300 \mathrm{~s}$ is presented in Table V.

\section{A. Case 1}

In this case, the performance of the proposed DADC is shown when the loads decrease. The electricity loads decrease by $630 \mathrm{~kW}$ and the thermal loads decrease by $280 \mathrm{~kW}$ at $300 \mathrm{~s}$.

Tables IV and V show the energy cost of each EH. More energy like gas and electricity are used by hub 1 to satisfy

TABLE III

CHP FUEL FUNCTION COEFFICIENTS AND CAPACITY

\begin{tabular}{cccccccc}
\hline Hub & $\bar{\alpha}$ & $\bar{\beta}$ & $\bar{\tau}$ & $\bar{\varepsilon}$ & $\bar{\lambda}$ & $\bar{\gamma}$ & $\begin{array}{c}\text { Capacity } \\
(\mathrm{e} / \mathrm{h})(\mathrm{kW})\end{array}$ \\
\hline 1 & 0.00331 & 0.98022 & 0.00311 & 0.94215 & 0.00201 & 21.67 & $320 / 520$ \\
\hline 2 & 0.00213 & 0.89365 & 0.00196 & 0.79631 & 0.00184 & 21.13 & $160 / 260$ \\
\hline 3 & 0.00221 & 0.92151 & 0.00180 & 0.76286 & 0.00188 & 19.82 & $80 / 130$ \\
\hline
\end{tabular}


TABLE IV

OPERATION OF HUBS BEFORE THE 300TH SECOND

\begin{tabular}{ccccccc}
\hline Hub & $\begin{array}{c}\text { output(e) } \\
(\mathrm{kW})\end{array}$ & $\begin{array}{c}\text { output(h) } \\
(\mathrm{kW})\end{array}$ & $\begin{array}{c}\text { input(e) } \\
(\mathrm{kW})\end{array}$ & $\begin{array}{c}\text { input(g) } \\
(\mathrm{kW})\end{array}$ & $\begin{array}{c}\operatorname{loss}(\mathrm{e}) \\
(\mathrm{kW})\end{array}$ & $\begin{array}{c}\operatorname{loss}(\mathrm{g}) \\
(\mathrm{kW})\end{array}$ \\
\hline 1 & 1861 & 897 & 3753.34 & 1247.17 & 1745.73 & 496.74 \\
2 & 929 & 445 & 1168.11 & 320.12 & 84.11 & 30.14 \\
3 & 463 & 224 & 590.65 & 174.11 & 36.19 & 41.55 \\
\hline
\end{tabular}

TABLE V

OPERATION OF HUBS AFTER THE 300TH SECOND

\begin{tabular}{ccccccc}
\hline $\begin{array}{c}\text { Case/ } \\
\text { Hub }\end{array}$ & $\begin{array}{c}\text { output(e) } \\
(\mathrm{kW})\end{array}$ & $\begin{array}{c}\text { output(h) } \\
(\mathrm{kW})\end{array}$ & $\begin{array}{c}\text { input(e) } \\
(\mathrm{kW})\end{array}$ & $\begin{array}{c}\text { input(g) } \\
(\mathrm{kW})\end{array}$ & $\begin{array}{c}\text { loss(e) } \\
(\mathrm{kW})\end{array}$ & $\begin{array}{c}\operatorname{loss}(\mathrm{g}) \\
(\mathrm{kW})\end{array}$ \\
\hline $1 / 1$ & 1541 & 764 & 2891.52 & 993.57 & 1219.97 & 360.18 \\
$1 / 2$ & 769 & 386 & 963.49 & 283.33 & 62.94 & 28.84 \\
$1 / 3$ & 383 & 189 & 495.35 & 152.01 & 33.89 & 41.46 \\
$2 / 1$ & 2179 & 1096 & 4771.21 & 1590.24 & 2398.32 & 687.69 \\
$2 / 2$ & 1092 & 548 & 1407.41 & 378.46 & 113.25 & 32.65 \\
$2 / 3$ & 545 & 273 & 696.16 & 203.98 & 40.17 & 41.97 \\
\hline
\end{tabular}

the loads since the inner devices of hub 1 need more fuel to meet loads as described in Tables II and III. To prove the proposed DADC based on IEIP could reduce energy consumption, a method that proportionally dispatches inner devices based on their capacities is presented to compare with the proposed method. The outputs of EHs are decided by the control of outputs based on consensus algorithm and the energy consumptions of the two method are shown in Tables VI and VII. The proposed method is denoted by A1 and the comparative method is denoted by A2. The objective of the proposed method is to reduce the total energy consumption when the outputs are controlled based on consensus algorithm. As shown in the two tables, single energy consumption of A1 may be slightly higher than A2, but the overall energy consumption of A1 is much lower than A2. Therefore, the objective is achieved by utilizing the proposed method. For other objectives such as carbon emissions, different energies have different effects on the objective. After the corresponding normalization, the DADC based on the IEIP proposed in this paper can still be used to resolve the issue.

As depicted in Fig. 5 (a), the thermal and electricity loads are proportionally shared by utilizing the proposed DADC. The stabilization time for electricity outputs is just about $0.2 \mathrm{~s}$. However, the heat outputs need more than $150 \mathrm{~s}$ to be stabilized. This different indicates that the heat supply network spend more time to achieve stabilized state than grid.

The variations of electricity and thermal loads induce the variations of the frequency and the outlet pressure. Based on the DADC, the frequency is restored to the reference value after electricity loads change as shown in Fig.5 (b). Similarly, the EHs can also restore the estimated outlet pressure to the

TABLE VI

OPERATION OF HUBS FOR DIFFERENT METHODS BEFORE THE 300TH SECOND

\begin{tabular}{ccccc}
\hline \multirow{2}{*}{ Hub } & $\begin{array}{c}\text { input(e)(kW) } \\
(\mathrm{A} 1 / \mathrm{A} 2)\end{array}$ & $\begin{array}{c}\text { input }(\mathrm{g})(\mathrm{kW}) \\
(\mathrm{A} 1 / \mathrm{A} 2)\end{array}$ & $\begin{array}{c}\operatorname{loss}(\mathrm{e})(\mathrm{kW}) \\
(\mathrm{A} 1 / \mathrm{A} 2)\end{array}$ & $\begin{array}{c}\operatorname{loss}(\mathrm{g})(\mathrm{kW}) \\
(\mathrm{A} 1 / \mathrm{A} 2)\end{array}$ \\
\hline \multirow{2}{*}{1} & $3753.34 /$ & $1247.17 /$ & $1745.73 /$ & $496.74 /$ \\
& 767.81 & 11655.31 & 189.74 & 9475.12 \\
\multirow{2}{*}{2} & $1168.11 /$ & $320.12 /$ & $84.11 /$ & $30.14 /$ \\
& 324.19 & 2467.43 & 37.41 & 1380.28 \\
\multirow{2}{*}{3} & $590.65 /$ & $174.11 /$ & $36.19 /$ & $41.55 /$ \\
& 182.64 & 841.97 & 38.28 & 299.33 \\
\hline
\end{tabular}

TABLE VII

OPERATION OF HUBS FOR DIFFERENT METHODS AFTER THE 300TH SECOND

\begin{tabular}{ccccc}
\hline Case/hub & $\begin{array}{c}\text { input(e)(kW) } \\
\text { (A1/A2) }\end{array}$ & $\begin{array}{c}\text { input(g)(kW) } \\
(\mathrm{A} 1 / \mathrm{A} 2)\end{array}$ & $\begin{array}{c}\text { loss(e)(kW) } \\
\text { (A1/A2) }\end{array}$ & $\begin{array}{c}\text { loss(g)(kW) } \\
\text { (A1/A2) }\end{array}$ \\
\hline \multirow{2}{*}{$1 / 1$} & $2891.52 /$ & $993.57 /$ & $1219.97 /$ & $360.18 /$ \\
& 644.72 & 8312.44 & 152.37 & 6499.85 \\
$1 / 2$ & $963.49 /$ & $283.33 /$ & $62.94 /$ & $28.84 /$ \\
& 287.22 & 1837.18 & 38.47 & 930.84 \\
$1 / 3$ & $495.35 /$ & $152.01 /$ & $33.89 /$ & $41.46 /$ \\
& 160.66 & 655.95 & 38.86 & 205.75 \\
$2 / 1$ & $4771.21 /$ & $1590.24 /$ & $2398.32 /$ & $687.69 /$ \\
& 963.35 & 15575.53 & 257.04 & 13006.98 \\
$2 / 2$ & $1407.41 /$ & $378.46 /$ & $113.25 /$ & $32.65 /$ \\
& 389.43 & 3218.22 & 36.28 & 1931.33 \\
$2 / 3$ & $696.16 /$ & $203.98 /$ & $40.17 /$ & $41.97 /$ \\
& 213.59 & 1059.39 & 37.66 & 417.22 \\
\hline
\end{tabular}

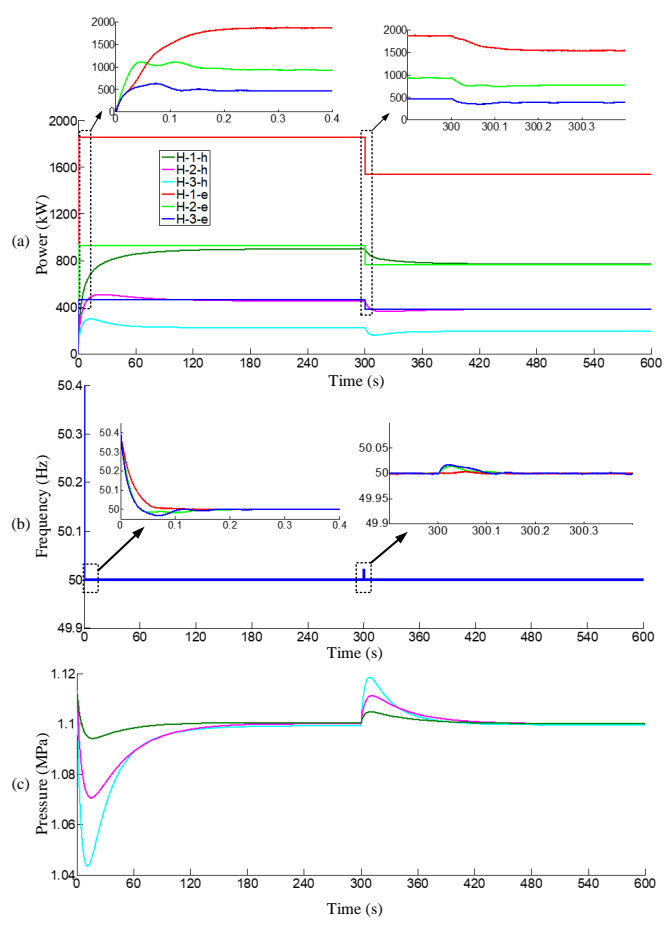

Fig. 5. The simulation diagram of case 1 .

reference pressure by using the proposed method as described in Fig. 5 (c). It validates that the DADC can reach the control objectives successfully without the information of lines.

\section{B. Case 2}

The effectiveness of DADC is tested under the situation in which the two kinds of loads both increase. In this case, electricity loads increase by $560 \mathrm{~kW}$ and thermal loads increase by $350 \mathrm{~kW}$.

As denoted in Fig. 6 (a), the thermal and electricity loads are shared upon the corresponding capacity of EH. Other diagrams in Fig. 6 express that the changing of parameters are negatively correlated with the variations of EH outputs. Meanwhile, all the parameters like frequency and pressure are restored to the reference by utilizing the proposed method. Table IV describes that both the loss of electricity and gas are increased with loads growth. Since the cost of the component element can be expressed by quadratic functions, it means more fuel is used 

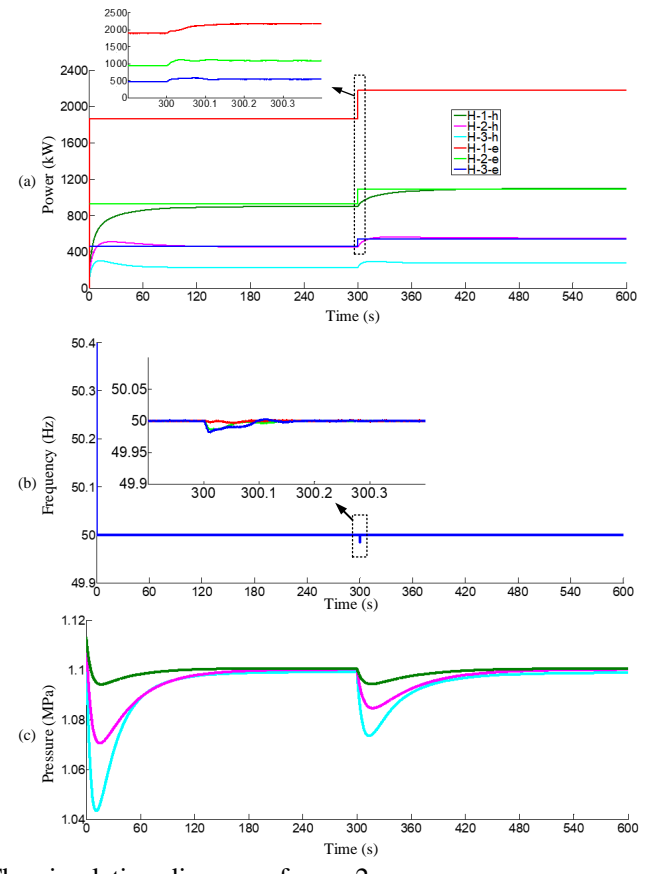

Fig. 6. The simulation diagram of case 2 .

to produce each unit of energy as the load increases. Namely, the loss will also increase.

\section{Case 3}

A comparative simulation of the DADC with two other methods, method 1 and method 2, is represented in case 3. Method 1 is the common approach that only considers the economic benefit as reference [6] and [8]. Method 2 is a control strategy investigated in reference [29] to realize the proportional allocation of the EH outputs. In this case, the frequency and pressure for each method are regulated to have the same value for a clearer presentation of the parameters variation. The electricity loads change from $4100 \mathrm{~kW}$ to $5100 \mathrm{~kW}$ and the thermal loads change from $2300 \mathrm{~kW}$ to $3000 \mathrm{~kW}$.

The outputs of EHs with method 1, method 2 and DADC are shown in Fig. 7 (a), (b) and (c), respectively. The variations of frequency and pressure are denoted in Fig. 7 (d) and (e), respectively. In Fig. 7(a), due to the low efficiencies of equipment in hub 1 , other hubs enter full-load working states respectively before 300 s by utilizing the method 1 . So only hub 1 can satisfy the variation of loads after 300s. In Fig. 7 (b), the electricity load power is accurately shared among hubs by using the method 2 because of the characteristic of the frequency. However, thermal load can not be shared proportionally when the information of the lines is unknown. Only the DADC can realize the proportional allocation of EH outputs without requiring the knowledge of the line resistances that is difficult to know. Moreover, the DADC can restore the changing of frequency but neither method 1 nor method 2 can realize as shown in Fig. 7 (d). Though the DADC can restore the estimated outlet pressure to the reference pressure, the practical outlet pressure can not be restored accurately owing to the line resistances as shown in Fig. 7 (e). Nevertheless, the
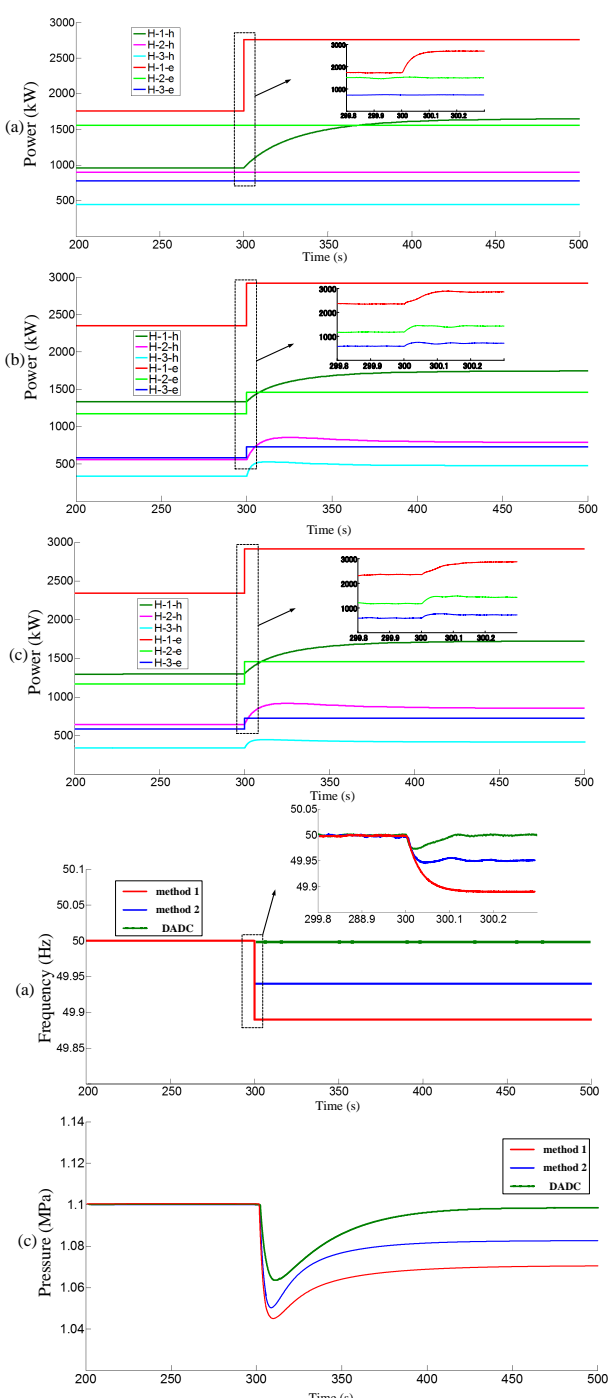

Fig. 7. The simulation diagram of case 3 .

fluctuation of pressure with the DADC is much lower than the fluctuation with other methods.

In case 3, the electricity and gas costs of the system controlled by the method 1 , method 2 and DADC are in total about $13550.7 \mathrm{~kW}, 14129.9 \mathrm{~kW}$ and $14196.6 \mathrm{~kW}$, respectively. The DADC costs more power than method 2 since method 2 does not consider the coupling characteristics of the devices and misses part of the energy loss. Moreover, method 2 can not achieve the proportional allocation of EHs.

In this context, the proposed DADC can share the loads power accurately among hubs without knowing the information of the resistances and has more benefits in security operation than other methods. However, a part of economic benefits is also sacrificed.

\section{Case 4}

The performance of the DADC impacted by faults on the electrical system is shown in the case. A EH will ignore the communication information of corresponding EHs when the outputs of corresponding EHs decrease sharply in a short time and its own output increases by utilizing the DADC. The parameters in the case are the same as other cases. The 

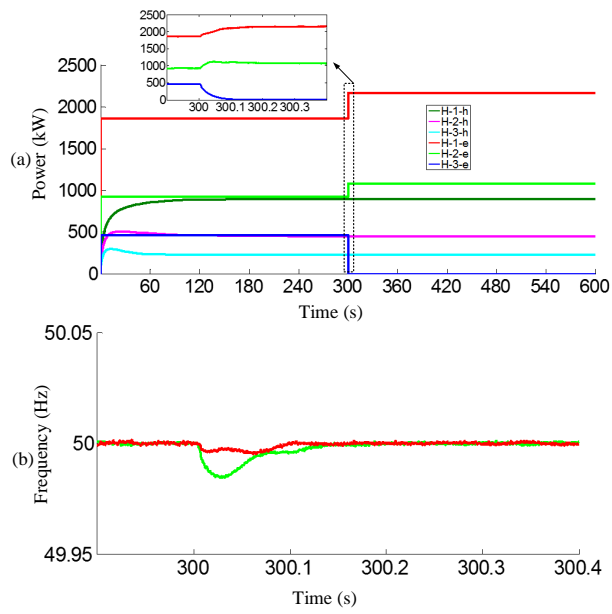

Fig. 8. The simulation diagram of case 4 .
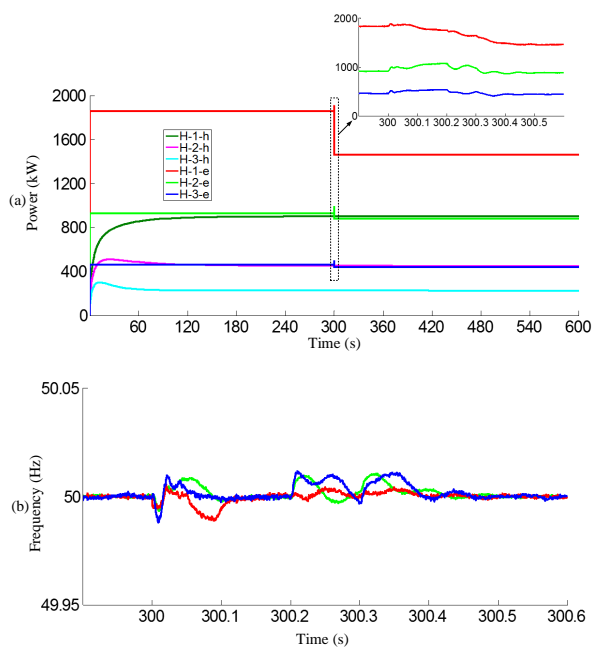

Fig. 9. The simulation diagram of case 5 .

power line of hub 3 is broken at 300s. As depicted in Fig. 8 (a), the electricity output of hub3 decreases to $0 \mathrm{~kW}$ in a short time since the power line of the $\mathrm{EH}$ is broken. The electricity outputs of other two hubs increase and realize the power sharing of loads. Since the DADC can avoid the impact between electricity output and heat output of EH that may cause severe fluctuation of system operation, the faults on the electrical system will not impact the heat output of EHs. As shown in Fig.8 (b), the frequency can also be restored to the reference value after electricity loads change.

As demonstrated in the case, the DADC can partially eliminate the impact of the fault on the electrical system. However, the proposed DADC can only allow available EHs to compensate loads, but not allow the unavailable EH corresponding to the fault line to recover to satisfy the loads. So the EHs may not satisfy the loads and the parameters may vary considerably from the reference value when several power lines or the power line which connects with a large capacity EH break.

\section{E. Case 5}

The uncertainties of renewable energy and loads are all considered in the case. To resolve the impact of the renewable energy uncertainty, the EH will change the nominal electricity
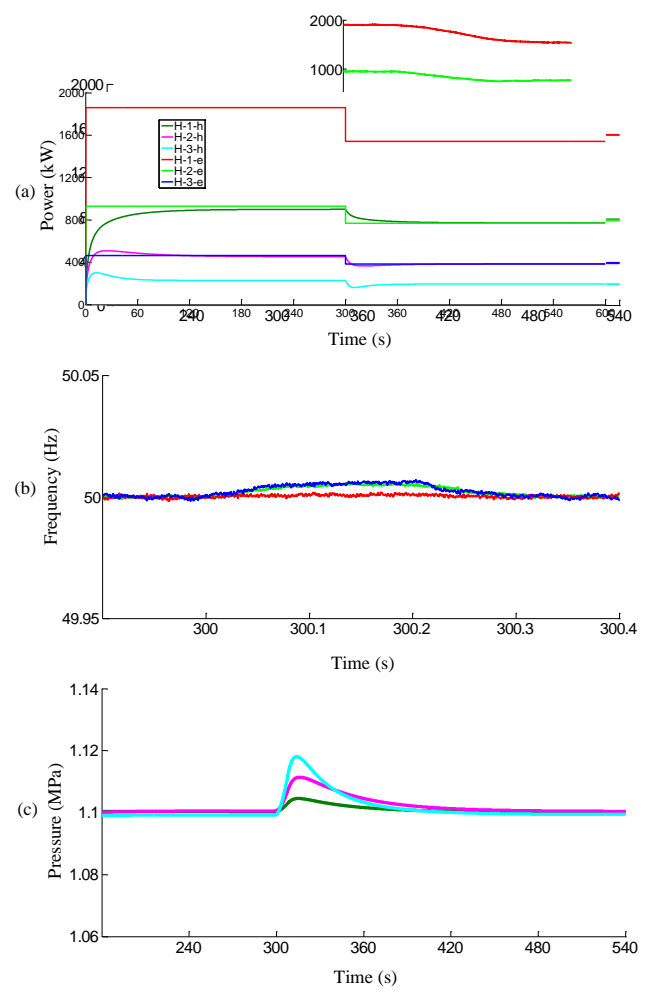

Fig. 10. The simulation diagram of case 6 .
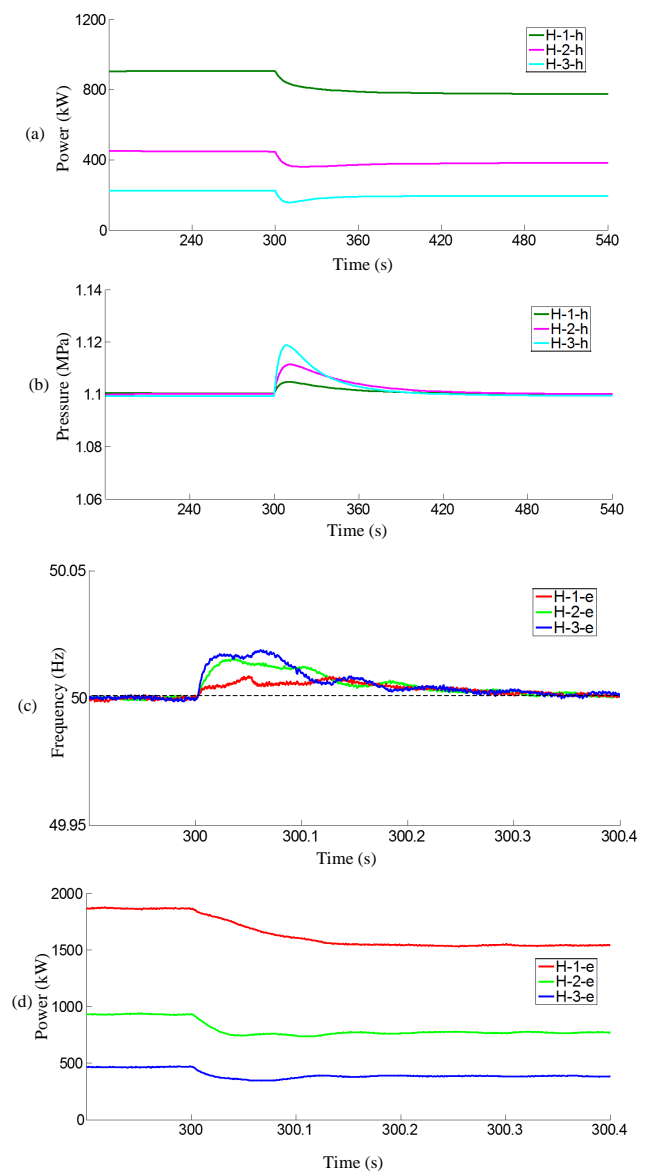

Fig. 11. The operation of EHs with the 100ms communication delays. 
output power according to the changes of renewable energy supply. Based on the equations (15)-(17), the electricity output of EH will respond to the changes of renewable energy supply to avid the overload of EH. The proposed DADC can accurately share the loads power and restore the deviations of parameters without knowing the load profiles in advance. Therefore, the control goals can still be achieved by utilizing the proposed method under severe loads uncertainties. Since thermal loads are stable in practice, the power load fluctuates sharply in a short time in the scenario under severe uncertainties to show the performance of the proposed method. In this case, the renewable energy supply of EH 1 decrease by $550 \mathrm{~kW}$ at $300 \mathrm{~s}$. The electricity loads increase by $210 \mathrm{~kW}$ at 300s. After the increasing, the electricity loads decrease by $360 \mathrm{~kW}$ and $390 \mathrm{~kW}$ at $300.2 \mathrm{~s}$ and $300.3 \mathrm{~s}$, respectively. The parameters in the case are the same as other cases.

Fig. 9 shows the effectiveness of the proposed DADC under severe uncertainties. The nominal electricity output power of hub 1 is changed after 300s. The power sharing can be realized based on the ratio of capacities after change and the outputs of EHs can be adjusted to follow the fluctuations of the load as shown in Fig. 9 (a). Fig. 9 (b) depicts that the EHs can still restore the deviations of parameters by utilizing the proposed DADC. The case shows that the DADC can reach the goal under severe uncertainties. Moreover, the actual load fluctuations are not as wild as in the case. So the proposed DADC can handle severe uncertainties to reach the control objectives as the case expressed.

\section{F. Case 6}

In this case, the performance of DADC under a more realistic scenario is tested. The parameters in the case are the same as other cases. The thermal loads decrease by $280 \mathrm{~kW}$ during $12 \mathrm{~s}$ and the electricity loads decrease by $630 \mathrm{~kW}$ during $0.2 \mathrm{~s}$ at $300 \mathrm{~s}$.

As denoted in Fig. 10, the electricity and thermal loads are proportionally shared and the system parameters are restored by utilizing the proposed DADC in a more realistic scenario. The electricity outputs need more time to be stabilized compared with case 1 due to the use of steps to perturb the system in case 1. The outputs of EHs need to be tuned consistently until the load stops changing. Compared with case 1, the changes in the heat outputs of EHs and the pressure are very slight and the stabilization time for heat outputs is not changed since the regulating speed of heat supply network is slow. Also, the stabilization time for heat outputs is much longer than the load change time.

\section{G. Case 7}

The performance of the DADC with communication delays is shown in the case. The parameters in the case are the same as case 1. Fig. 11 shows the operation of EHs with the $100 \mathrm{~ms}$ communication delays and the operation of EHs with the 300ms communication delays is shown in Fig. 12.

As shown in Fig. 11 and Fig. 12, the heat outputs of EHs are not influenced by the communication delays since the regulation speed of heat network is slow. The EHs can
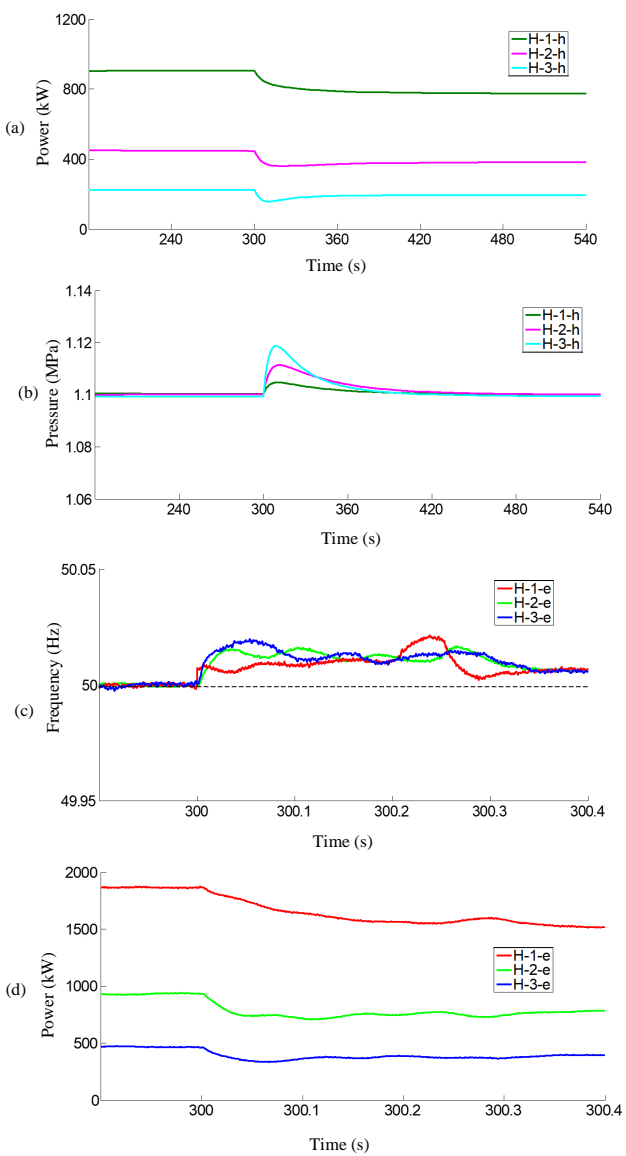

Fig. 12. The operation of EHs with the 300ms communication delays.

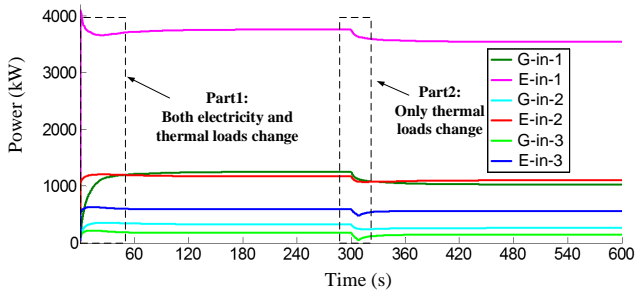

Fig. 13. The simulation diagram of case 8 .

achieve the control objectives with the $100 \mathrm{~ms}$ communication delays. However, with the $300 \mathrm{~ms}$ communication delays, the restoration of frequency cannot be realized and the electricity outputs of EHs begin to fluctuate.

\section{H. Case 8}

This case is presented to show the energy-coupling of the EI. In this case, the thermal loads decrease by $440 \mathrm{~kW}$ at $300 \mathrm{~s}$. The parameters in the case are the same as other cases. The inputs of EHs during the operation in the case are shown in Fig. 13. Part 1 shows the inputs of EHs when electricity loads and thermal loads change simultaneously. The inputs of EHs with only thermal loads changes are shown in part 2 .

As shown in the part 1 of Fig. 13, EH will immediately obtain the energy from energy sources to meet the power load demand changes by the control of outputs. After that, CHP, boiler and furnace start to be regulated based on the control of inner devices. The inputs of $\mathrm{EH}$ are also adjusted to meet the 


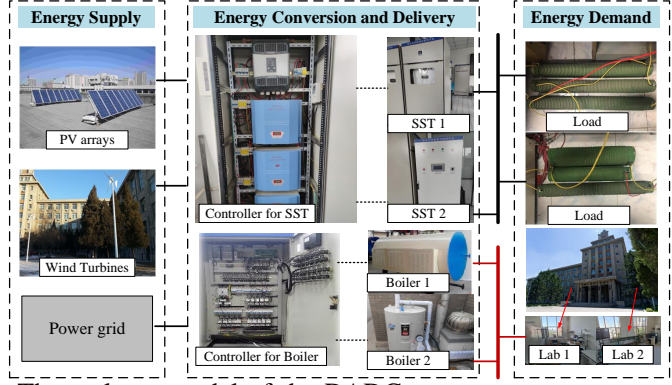

Fig. 14. The real test model of the $\overline{\mathrm{DADC}}$.
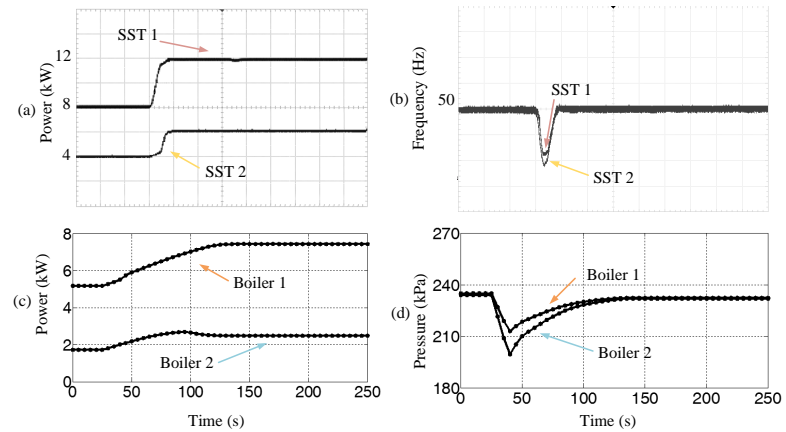

Fig. 15. The results of a real test.

requirements of internal control and the demands of electricity and heat. In this way, the changes of electricity output and heat output will not affect each other, and avoid the influence of the system. Thermal loads change can cause both electricity and gas inputs change as shown in part 2, which expressed the energy is coupled in EI. It is observed that the DADC decide the operation of the EH and resolve the energy-coupling issue.

\section{EXPERIMENT RESULTS}

A scaled-down networked integrated energy system is shown in Fig. 14. Based on the integrated energy system, a real test is proposed to verify the proposed method. The integrated energy system is consisted by three parts: energy supply, energy conversion and delivery, energy demand. There are two solid state transformers (SST) and two boilers in the system. The SST 1 consists of 9kW PV arrays and 5kW wind turbines, while the SST 2 consists of $7 \mathrm{~kW}$ PV arrays. The capacity of boiler 1 is $30 \mathrm{~kW}$ and the capacity of boiler 2 is $10 \mathrm{~kW}$. The electricity loads that switch between "light" and "heavy" condition are considered for the system. The light load is $12 \mathrm{~kW}$ and the heavy load is $18 \mathrm{~kW}$. Two labs are utilized as thermal loads, while the areas of the two labs are 72 square meters and 33 square meters respectively. The reference values of frequency and pressure are $50 \mathrm{~Hz}$ and $235 \mathrm{kPa}$, respectively.

Fig. 15 shows the results of the test. The outputs of SSTs are denoted in Fig. 15 (a) (scales: 2kW/div, 0.2s/div) and the changes of the frequency are depicted in Fig. 15 (b) (scales: $0.05 \mathrm{~Hz} / \mathrm{div}, 0.2 \mathrm{~s} / \mathrm{div}$ ). Since the heat outputs regulates slowly, the data of boilers is recorded every $5 \mathrm{~s}$. The output power and pressure of boilers are shown in Fig. 15 (c) and Fig. 15 (d) based on the data. As observed, power sharing and parameters restoration are realized by utilizing the proposed DADC in the test.

\section{CONCLUSION}

This paper proposed an DADC that employs both consensus algorithm and IEIP. An architecture of multi-agent system for the EI has been formulated. The deducing process of consensus-based control of $\mathrm{EH}$ outputs has been investigated. The control of outputs enables EHs accurately share the loads power without knowing the information of the line resistances which is hard to know. Furthermore, the proposed control strategy realizes the restoration of frequency and average pressure to recover the changing of system parameters induced by the droop action. The control of component elements has been represented to minimize the energy consumption. The DADC has been tested on the EI with three hubs. Three case studies have shown that the DADC can achieve the proportional allocation of the outputs and recover the deviations of the parameters. Meanwhile, the consequences of cases also denoted the effectiveness of the control for inner deceives.

However, the communication environment may influence the effectiveness of the DADC. Different situations such as network attack, communication failure, noise and other problems have different solutions. The research focuses of this paper are how to achieve the control objectives by using the network characteristics of different energy networks and how to handle the energy-coupling characteristic. The performance of the cooperative control in EI with the influence of communication will be put in focus by authors later.

\section{REFERENCES}

[1] A .Q. Huang, M. L. Crow et al.,"The future renewable electric energy delivery and management (freedm) system: the energy internet," Proc. IEEE., vol. 99, no. 1, pp. 133-148, Nov 2011.

[2] H. Zhang, Y. Li et al., "Distributed optimal energy management for energy internet," IEEE Trans. Ind. Informat., vol. 13, no. 6, pp. 3081-3097, 2017.

[3] H. Xiao, W. Pei et al., "Bi-level planning for integrated energy systems incorporating demand response and energy storage under uncertain environments using novel meta model," CSEE Journal of Power and Energy Systems., vol. 4, no. 2, pp. 155-167, 2018.

[4] G. Martin, K. Gaudenz et al., "Energy hubs for the future," IEEE Power Energy Mag., vol. 5, no. 1, pp. 24-30, 2007.

[5] R. Evins and K. Orehounig et al., "New formulations of the 'energy hub' model to address operational constraints," Energy., vol. 73, pp. 387-398, 2014.

[6] I. G. Moghaddam, M. Saniei et al., "A comprehensive model for selfscheduling an energy hub to supply cooling, heating and electrical demands of a building," Energy., vol. 94, pp. 157-170, 2016.

[7] M. H. Barmayoon, M. F. Firuzabad et al., "Energy storage in renewablebased residential energy hubs," IET Gener. Transm. Distrib., vol. 10, no. 13, pp. 3127-3134, Jun 2016.

[8] K. Orehounig, R. Evins et al., "Integration of decentralized energy systems in neighbourhoods using the energy hub approach," Applied Energy., vol. 154, pp. 277-289, 2015.

[9] H. Yang, T. Xiong et al., "Optimal operation of DES/CCHP based regional multi-energy prosumer with demand response," Applied Energy., vol. 167, pp. 353-365, 2016.

[10] S. Faraz, F. Michael et al., "An energy demand model for a fleet of plug-in fuel cell vehicles and commercial building interfaced with a clean energy hub," Int. J. Hydrogen Energy., vol. 35, pp. 5154-5163, 2010.

[11] M. Azadeh, F. Michael et al., "Mixed integer linear programing based approach for optimal planning and operation of a smart urban energy network to support the hydrogen economy," Int. J. Hydrogen Energy., vol. 41, pp. 7700-7716, 2016.

[12] M. Yaser, A. Ali et al., "Energy hub based on nuclear energy and hydrogen energy storage," Ind. Eng. Chem. Res., vol. 52, pp. 7470-7481, 2013. 
[13] A. Kamal, F. Michael et al., "Integration of renewable energy sources into combined cycle power plants through electrolysis generated hydrogen in a new designed energy hub," Int. J. Hydrogen Energy., vol. 41, pp. 16718-16728, 2016.

[14] A. Sheikhi et al., "Integrated demand side management game in smart enerrgy hubs," IEEE Trans. Smart Grid., vol. 6, no. 2, pp. 675-683, 2015.

[15] S. Bahrami and A. Sheikhi, "From demand response in smart grid toward integrated demand response in smart energy hub," IEEE Trans. Smart Grid., vol. 7, no. 2, pp. 650-658, 2016.

[16] A. Sheikhi, S. Bahrami et al., "An autonomous demand response program for electricity and natural gas networks in smart energy hubs," Energy., vol. 89, pp. 490-499, 2015.

[17] Y. Cheng, N. Zhang et al. "Low-carbon operation of multiple energy systems based on energy-carbon integrated prices," IEEE Trans. Smart Grid., 2019, DOI:10.1109/TSG.2019.2935736.

[18] A. Najafi, H. Falaghi et al., "Medium-term energy hub management subject to electricity price and wind uncertainty," Appl. Energy., vol. 168, pp. $418-433,2016$

[19] S. Pazouki and M. R. Haghifam, "Optimal planning and scheduling of energy hub in presence of wind, storage and demand response under uncertainty," Int. J. Elec Power, vol. 80, pp. 219-239, 2016.

[20] A. Dolatabadi, M. Jadidbonab et al., "Short-term scheduling strategy for wind-based energy hub: a hybrid stochastic/igdt approach," IEEE Trans. Sustain. Energy., 2019, DOI:10.1109/TSTE.2017.2788086.

[21] A. Vaccaro, C. Pisani et al., "Affine arithmetic-based methodology for Energy Hub operation-scheduling in the presence of data uncertainty," IET Gener. Transm. Distrib., vol. 9, no. 13, pp. 1544-1552, 2015.

[22] M. Majidi and K. Zare, "Integration of smart energy hubs in distribution networks under uncertainties and demand response concepts," IEEE Trans. Power Syst., vol. 34, no. 1, 2019.

[23] A. Bidram, A. Davoudi , "Hierarchical structure of microgrids control system ," IEEE Trans. Smart Grid., vol. 3, no. 4, 2012

[24] K. De Brabandere, B. Bolsens, et al., "A voltage and frequency droop control method for parallel inverters," IEEE Trans. Power Syst., vol. 22, no. 4, pp. 1107-1115, 2007.

[25] J. Simpson-Porco, F. Dorfler, F. Bullo, "Synchronization and power sharing for droop-controlled inverters in islanded microgrids ," Automatica., vol. 49, no. 9, pp. 2603-2611, 2013.

[26] H. Zhang, S. Kim, Q. Sun et al., " Distributed adaptive virtual impedance control for accurate reactive power sharing based on consensus control in microgrids," IEEE Trans. Smart Grid., vol. 8, no. 4, pp. 1-13, 2016.

[27] J. Simpson-Porco, Q. Shafiee, F. Dorfler et al., " Secondary frequency and voltage control of islanded microgrids via distributed averaging," IEEE Trans. Ind. Electron., vol. 212, pp. 850-867, 2018.

[28] F. Guo, C. Wen et al., " Distributed secondary voltage and frequency restoration control of droop-controlled inverter-based microgrids," IEEE Trans. Ind. Electron., vol. 62, no. 7, pp. 4355-4364, 2015.

[29] Q. Sun, N. Zhang et al., "The dual control with consideration of security operation and economic efficiency for energy hub," IEEE Trans. Smart Grid., 2019, DOI:10.1109/TSG.2019.2893285.

[30] E. M. Davidson, S. D. J. McArthur et al., "Applying multi-agent system technology in practice: Automated management and analysis of SCADA and digital fault recorder data," IEEE Trans. Power Syst., vol. 21, no. 2, pp. 559-567, 2006.

[31] J. A. Hossack, J. Menal et al., "A multiagent architecture for protection engineering diagnostic assistance," IEEE Trans. Power Syst., vol. 18, no. 2 , pp. 639-647, 2003

[32] M. Wooldridge, N. R. Jennings et al., "The Gaia methodology for agentoriented analysis and design," J. Auton. Agents Multi-Agent Syst., vol. 3 , no. 3, pp. 285-312, 2000.

[33] C. Shao,Y. Ding et al., "Modeling and integration of flexible demand in heat and electricity integrated energy system," IEEE Trans.Sustainable Energy., vol. 9, pp. 361-370, 2018.

[34] Z. Qu, Cooperative control of dynamical systems: applications to autonomous vehicles, New York: Springer-Verlag, 2009.

[35] A. Wood, B. Wollenberg,Power generation, operation and control. 2nd ed., New York: Wiley, 1996.

[36] H. Xin, H. Zhao et al., "A decentralized hierarchical control structure and self-optimizing control strategy for f-p type dgs in islanded microgrids," IEEE Trans. Smart Grid., vol. 7, no. 1, pp. 3-5, 2016.

[37] IU. Nutkani, PC. Loh, et al., "Droop scheme with consideration of operating costs," IEEE Trans. Power. Electron., vol. 29, pp. 1047-1052, 2014.

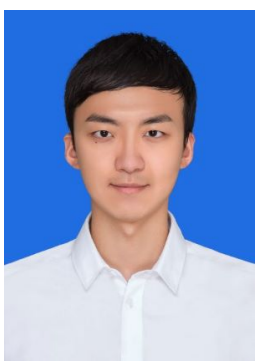

Ning Zhang received the B.S. degree in electrical engineering from the Hebei University, China, in 2015 and the M.S. degree in electrical engineering from the Northeastern University, Shenyang, in 2017. He is currently pursuing his Ph.D. degree in the School of Information Science and Engineering, Northeastern University, China.

His research interests are scheduling strategy of energy hub, security operation of multi-carrier energy system and energy trading.

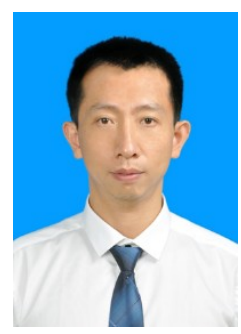

Qiuye Sun (M'11-SM'19) received the B.S. degree in power system and its automaton from the Northeast Dianli University of China, Jilin City, China, in 2000, the M.S. degree in power electronics and drives, and the Ph.D. degree in control theory and control engineering from the Northeastern University, Shenyang, China, in 2004 and 2007, respectively. Since 2014, he has been a Full Professor with the School of Information Science and Engineering, Northeastern University, China.

His main research interests are Optimization Analysis Technology of Power Distribution Network, Network Control of Distributed Generation System, microgrids, and Energy Internet. He has authored and coauthored over 280 journal and conference papers, six monographs and co-invented 90 patents.

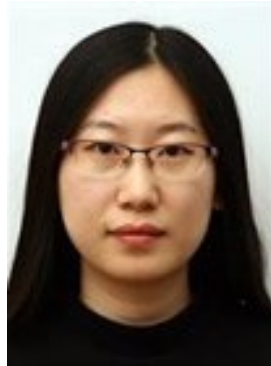

Jiawei Wang received the B.E. degree in automation from the Northeastern University, China, in 2014. She received the M.E. and $\mathrm{PhD}$ degree in electrical engineering from the Technical University of Denmark, Denmark, in 2016 and 2020 respectively.

Her research interests include integrated energy system, combined heat and power, power system operation and electricity market.

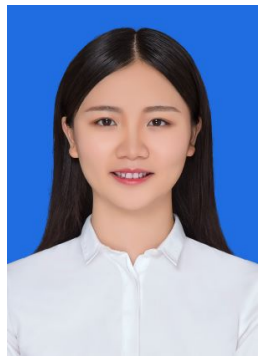

Lingxiao Yang received the B.S. degree in Electrical Engineering from Henan Normal University, China, in 2015 and the M.S. degree in Electrical Engineering from Northeastern University, Shenyang, in 2017, where she is currently pursuing the Ph.D. degree with the School of Information Science and Engineering.

Her research interests include machine learning and its various applications in energy internet, microgrids, power distribution network. 